\title{
The challenge of treating central nervous system infections
}

\section{U K Ranawaka}

Ceylon Medical Journal 2015; 60: 155-158
Central nervous system (CNS) infections produce large numbers of death and disability. For example, 17$33 \%$ of patients with bacterial meningitis die in spite of appropriate antibiotic therapy [1-3]. Case fatality rates can be as high as $44 \%$ in tuberculous meningitis (TBM) [4], and $20-30 \%$ in Japanese encephalitis (JE), the commonest viral encephalitis worldwide [5]. Many of the survivors are left with residual neurological sequelae; $30-54 \%$ after bacterial meningitis [3, 6], up to $47 \%$ after TBM [4, 7], and about $50 \%$ after JE [5]. CNS infections are of special concern to clinicians in developing countries, as they are commoner and produce more deaths and disability in these regions [8]. Early treatment is imperative. In bacterial meningitis, delays in treatment are associated with excess mortality and residual neurological deficits whereas early treatment has been shown to improve outcome [2, 9]. Recent advances in knowledge have helped guide treatment, especially in bacterial meningitis, but many questions remain.

\section{Getting the diagnosis right - how useful are the clinical features?}

Delivering appropriate treatment early depends on rapid and accurate diagnosis, but clinical diagnosis can be difficult. The clinical spectrum of CNS infections is wide (meningitis, encephalitis, brain abscess), the possible causes are diverse (bacterial, tuberculous, viral, fungal, etc), yet the clinical presentation is frustratingly similar, with a varying combination of fever, headache, nausea, vomiting, altered consciousness, seizures, focal neuro-logical deficits and meningism. Clinical findings are unhelpful in predicting the type of CNS infection [10]. In a meta-analysis, Attia et al found that typical symptoms had low sensitivity for detecting meningitis (headache- 50\%, nausea and vomiting- 30\%, altered mental state- $67 \%$ ) [11]. The triad of fever, neck stiffness and altered mental state is seen in only $44-46 \%[1,3$,
11, 12]. Thomas et al observed that traditional signs of meningeal irritation were poor predictors of meningitis. The sensitivity was $30 \%$ for neck stiffness, and only $5 \%$ for Kernig's sign and Brudzinski's sign [13]. Other signs such as active neck flexion and jolt accentuation of headache, although less well known, are more sensitive for meningeal irritation $[10,11,14]$. The clinical features may be more useful in 'ruling-out', rather than 'ruling-in' a diagnosis of meningitis. Although the sensitivity is very low, the specificity for Kernig's sign and Brudzinski's sign is high at $95 \%$ [13]. At least one of the triad of fever, neck stiffness and altered mental state is seen in $99-100 \%$, and the absence of all three virtually eliminates the diagnosis $[1,11]$.

\section{Getting the diagnosis right - how useful are laboratory investigations?}

As clinical clues are unreliable, establishing the diagnosis depends on laboratory investigations. Cerebrospinal fluid (CSF) analysis is the mainstay in diagnosis, and CSF cytology, biochemistry and staining provide the most helpful data in initial decision making. Independent predictors of bacterial meningitis on CSF analysis include CSF: blood glucose ratio less than 0.23 , protein more than $2.2 \mathrm{~g} / \mathrm{L}$, leucocyte count more than $2000 / c c$, and a polymorphonuclear leucocyte count more than $1180 / \mathrm{cc}$ [15]. However, such changes reflect more severe infection, and are seen in only a minority of cases. CSF cytology can be negative in up to $10 \%$ with bacterial meningitis and importantly, these patients may have worse outcomes $[12,16]$. Simple microbiological staining measures can be helpful but unreliable. Gram staining of CSF has good specificity in bacterial meningitis (up to $97 \%$ ), but can be negative in $40-75 \%$ depending on the concentration of microorganisms [14]. In TBM, sensitivity of Ziehl-Nielsen staining for acid-fast bacilli is only $5-30 \%[17]$.

Department of Medicine, Faculty of Medicine, University of Kelaniya, Sri Lanka.

Correspondence: UKR, e-mail: <udayaran@yahoo.com>. Received 24 August 2015. 
Targeted treatment then requires isolation of the organisms in blood culture or CSF, but this is difficult in developing countries where it really matters, largely due to inadequate diagnostic facilities. Blood cultures are positive in about two-thirds of patients with bacterial meningitis in developed countries [8, 12], but rates fall to less than one-third in the developing world $[8,18$, 19]. CSF isolation rates are high (60-73\%) in developed countries $[1,12,15]$, but much lower (3-35\%) in developing countries $[8,20,21,22,23]$. In a Sri Lankan study of 215 adults with suspected CNS infection, a definitive microbiological diagnosis was established in only one patient [24]. In another Sri Lankan study of children $<5$ years, an organism was isolated in only $2.3 \%$ of CSF specimens [21]. Previous antibiotic use may be an important reason for poor diagnostic yield, and high rates are reported from many parts of the developing world (Vietnam $-61 \%$, Pakistan $->50 \%$, Nepal $-26.7 \%$, Sri Lanka - 32\%) [18, 22, 23, 24]. This is in contrast to the low rates of prior antibiotic use (usually less than 10\%) from developed countries [3].

Early diagnosis, therefore, requires tests that do not depend on the presence of live organisms. The advent of the polymerase chain reaction (PCR) based assays for nucleic acid detection has revolutionized microbiological diagnosis in CNS infection. They are rapid, more sensitive and specific, and are not affected by prior antibiotic treatment, thus improving timely and accurate diagnosis [25]. PCR based assays are especially important in viral infections, where traditional methods fail to confirm the causes. However, they are not readily available in developing countries, and their introduction in such settings has been shown to improve the diagnostic yield [26].

\section{Getting the diagnosis right - Are we missing something?}

Inadequate diagnostic facilities and prior antibiotic use, may not be the only reasons for poor diagnostic yields. A closer analysis of the literature reveals that betweenstudy comparisons can be misleading. Most previous studies reporting high isolation rates are from case series with a selected syndrome (bacterial meningitis, viral encephalitis, etc.), with many of them being retrospective studies [1, 2, 3, 12]. Many such series describe only microbiologically proven cases $[2,3,12]$, and would naturally show higher isolation rates. In contrast, studies of unselected patients with presumed CNS infection have produced much lower isolation rates, even from developed countries [27, 28, 29, 30]. Such data are more relevant for 'point of care' clinical decision making in the acute stage, as patients do not present with a diagnostic label of 'bacterial meningitis' or 'viral encephalitis', but with a diagnostically challenging clinical syndrome of febrile meningo-encephalopathy. In a multicentre study from UK, only $20 \%$ were found to have a CNS infection out of 217 suspected patients, and CSF culture was positive in only 3 out of 199 samples [27]. In another study in UK, $60 \%$ of the cases were of unknown aetiology [30]. In the California Encephalitis Project, a confirmed or probable cause was found in only $16 \%$ of patients, and an aetiological agent was not found in $62 \%$ despite extensive testing [29]. Up to $85 \%$ of cases worldwide are reported to be due to undetected causes [28].

It is important to look beyond the usual suspects for such low diagnostic yields. Increasing global travel can introduce previously unseen organisms to new territories. We may well have been ignoring the possibility of a different spectrum of neurotropic organisms that are not detected by the traditional microbiological investigations. Several hitherto unsuspected agents, such as Bocavirus and Cyclovirus, have been recently isolated in CSF of Sri Lankan patients with CNS infections. [31, 32]. Furthermore, several non-infectious syndromes such as paraneoplastic and immune-mediated encephalitis are well described, and recent reports indicate that they may be at least as common as infectious causes [28, 33]. In a multicentre study of patients with encephalitis in UK, only $42 \%$ of cases were attributed to infections, and $21 \%$ had immune-mediated encephalitis [28]. In patients aged $<30$ years in the California Encephalitis Project, immunemediated encephalitis due to anti-N-methyl-D-aspartate receptor (anti-NMDAR) antibodies was commoner than those due to viral aetiologies [33].

\section{Getting the treatment right}

As laboratory diagnosis is difficult, and delays in treatment are unacceptable, urgent antimicrobial treatment has to be commenced on an empiric 'best guess' basis. The choice of drugs would ideally depend on local epidemiological data of prevalence of causative organisms and antibiotic sensitivity patterns. Such data, however, are lacking from developing countries. Current guidelines recommend the use of third generation cephalosporins in suspected bacterial meningitis, with the addition of vancomycin in areas of high levels of penicillin and cephalosporin resistance in $S$. pneumoniae [14, 15], but these recommendations are based on data from developed countries. In Sri Lanka, there are no prevalence data on the aetiology of CNS infections to guide empiric therapy. Previous published work have been largely confined to case series of specific syndromes [20, 21, 34, 35, 36]. Available data suggest alarmingly high rates of antibiotic resistance in Sri Lankan patients. Among pneumococcal isolates from children, penicillin resistance was seen in $91 \%$, and cefotaxime resistance in 48\% [20]. Addition of intravenous acyclovir to the antibiotic regimen is generally recommended in initial empiric therapy, and is routinely practiced by most clinicians [15]. However, acyclovir is effective in only Herpes simplex virus and 
varicella encephalitis, and there is no evidence to support its routine use in all suspected cases. Uncertainty in early diagnosis therefore would lead to further uncertainty in early treatment, and add significantly to cost of care.

The mortality in bacterial meningitis is related to CNS inflammation, rather than direct effects of infection. Treatment induced bacterial lysis triggers a cascade of inflammatory events that includes release of inflammatory cytokines, excitotoxicity and oxidative damage, leading to cytotoxic and vasogenic oedema, increasing intracranial pressure and neuronal dysfunction and death [10, 14, 15]. Steroids have been shown to attenuate this inflammatory response, inhibit cytokine synthesis, decrease CSF outflow resistance and stabilize the blood-brain barrier [10, 14]. This knowledge has been translated into clinical trial benefits, with intravenous dexamethasone shown to be effective in reducing mortality and long term neurological sequelae $[15,37,38]$. There are, however, several issues related to steroid therapy in meningitis. Initial concerns included possible lack of benefit in non- $H$. influenzae meningitis in children, and poor CSF penetration of antibiotics (especially vancomycin) with stabilization of the blood-brain barrier [14], but these concerns have now being allayed [39]. Another concern is that steroids may have no value in treating meningitis in low income countries [39], but this assumption is based on the lack of efficacy seen in studies from areas of high HIV prevalence $[19,40]$. Currently, intravenous dexamethasone, commenced before or with the first dose of antibiotic, is recommended for adults and children with community acquired meningitis [10, 15, 38, 39].

The place of steroids is less clear in other acute CNS infections. After initial skepticism, steroids are now recommended in TBM [41], based on several clinical trials showing reductions in death and disability [42, 43]. There is no evidence of benefit in using steroids in viral encephalitis. Therefore, accurate aetiological diagnosis is necessary in deciding on steroid use, but this is not usually possible in the first few hours when steroids should be started with the first dose of empiric antibiotic therapy.

\section{The challenge for Sri Lanka?}

Getting the treatment right in the critical first few hours depends on getting the diagnosis right. This is particularly challenging in developing countries like Sri Lanka where CNS infections are more prevalent, due to a combination of lack of rapid diagnostic facilities, widespread prior antibiotic use, and lack of epidemiological data. There is a clear need for research into the aetiology of acute CNS infections and local antibiotic sensitivity patterns. Searching beyond the traditional diagnostic paradigms for previously unsuspected infectious agents and noninfectious causes deserves more attention. Use of newer diagnostic tools and newer antibiotics would add to the cost of care, but this would be money well spent, on minimising disability and saving lives.

\section{Conflicts of interests}

There are no conflicts of interest.

\section{References}

1. Durand ML, Calderwood SB, Weber DJ, et al. Acute bacterial meningitis in adults: a review of 493 episodes. $N$ Engl J Med 1993; 328: 21-28.

2. Køster-Rasmussen R, Korshin A, Meyer CN. Antibiotic treatment delay and outcome in acute bacterial meningitis. $J$ Infec 2008; 57: 449-54.

3. Weisfelt M, van de Beek D, Spanjaard L, Reitsma JB, de Gans J. Clinical features, complications, and outcome in adults with pneumococcal meningitis: a prospective case series. Lancet Neurol 2006; 5: 123-9.

4. Hosoglu S, Ayaz C, Geyik MF, Kökoglu OF, Ceviz A. Tuberculous meningitis in adults: an eleven-year review. Int J Tuberc Lung Dis 1998; 2: 553-7.

5. Solomon T, Dung NM, Kneen R, Gainsborough M, Vaughn DW, Khanh VT. Japanese encephalitis. J Neurol Neurosurg Psych 2000; 68: 405-415.

6. Bohr V, Paulson OB, Rasmussen N. Pneumococcal meningitis: late neurologic sequelae and features of prognostic impact. Arch Neurol 1984; 41: 1045-9.

7. Farinha NJ, Razali KA, Holzel H, Morgan G, Novelli VM. Tuberculosis of the central nervous system in children: a 20-year survey. $J$ Infect 2000; 41: 61-8.

8. Scarborough M, Thwaites GE. The diagnosis and management of acute bacterial meningitis in resource-poor settings. Lancet Neurol 2008; 7: 637-48.

9. Proulx N, Frechette D, Toye B, Chan J, Kravcik S. Delays in the administration of antibiotics are associated with mortality from adult acute bacterial meningitis. QJM 2005; 98: 291-98.

10. Fitch MT, van de Beek D. Emergency diagnosis and treatment of adult meningitis. Lancet Infect Dis 2007; 7: 191-200.

11. Attia J, Hatala R, Cook DJ, Wong JG. The rational clinical examination. Does this adult patient have acute meningitis? JAMA 1999; 282: 175-81.

12. van de Beek D, de Gans J, Spanjaard L, Weisfelt M, Reitsma JB, Vermeulen M. Clinical features and prognostic factors in adults with bacterial meningitis. $N$ Engl J Med 2004; 351: $1849-59$.

13. Thomas KE, Hasbun R, Jekel J, Quagliarello VJ. The diagnostic accuracy of Kernig's sign, Brudzinski's sign, and nuchal rigidity in adults with suspected meningitis. Clin Infect Dis 2002; 35: 46-52.

14. Anon. Bacterial meningitis. Continuum (Minneap Minn) 2002: 8: 7-26. 
15. Bartt R1. Acute bacterial and viral meningitis. Continuum (Minneap Minn) 2012; 18: 1255-70.

16. van de Beek D, de Gans J, Tunkel AR, Wijdicks EF. Community-acquired bacterial meningitis in adults. $N$ Engl J Med 2006; 354: 44-53.

17. Zunt JR1, Baldwin KJ. Chronic and subacute meningitis. Continuum (Minneap Minn) 2012; 18: 1290-318.

18. Nguyen TH, Tran TH, Thwaites G, et al. Dexamethasone in Vietnamese adolescents and adults with bacterial meningitis. N Engl J Med 2007; 357: 2431-40.

19. Scarborough $\mathrm{M}$, Gordon SB, Whitty CJ, et al. Corticosteroids for bacterial meningitis in adults in sub-Saharan Africa. $N$ Engl J Med 2007; 357: 2441-50.

20. Batuwanthudawe R, Karunarathne K, Dassanayake M, et al. Surveillance of invasive pneumococcal disease in Colombo, Sri Lanka. Clin Infect Dis 2009; 48 (Sup 2): S136-40.

21. Batuwanthudawe R, Rajapakse L, Somaratne P, Dassanayake M, Abeysinghe N. Incidence of childhood Haemophilus influenzae type b meningitis in Sri Lanka. Int J Infect Dis 2010; 14: e372-6.

22. Shah AS, Knoll MD, Sharma PR, et al. Invasive pneumococcal disease in Kanti Children's Hospital, Nepal, as observed by the South Asian Pneumococcal Alliance network. Clin Infect Dis 2009; 48 (Sup 2): S123-8.

23. Zaidi AK, Khan H, Lasi R, Mahesar W; Sindh Meningitis Group. Surveillance of pneumococcal meningitis among children in Sindh, southern Pakistan. Clin Infect Dis 2009; 48 (Sup 2): S129-35.

24. Ranawaka UK, Rajindrajith EG, Perera KV, Dassanayake KM, Premaratne BA, de Silva HJ. Clinical profile and difficulties in diagnosis of central nervous system infections in adult patients in a tertiary care hospital. Ceylon Med $J$ 2013; 58: $26-8$

25. Stockdale AJ, Weekes MP, Aliyu SH. An audit of acute bacterial meningitis in a large teaching hospital 2005-10. QJM 2011; 104: 1055-63.

26 Sacchi CT, Fukasawa LO, Gonçalves MG, et al. Incorporation of real-time PCR into routine public health surveillance of culture negative bacterial meningitis in São Paulo, Brazil. PLoS One 2011; 6: e20675.

27. Michael BD, Sidhu M, Stoeter D, et al. Acute central nervous system infections in adults - a retrospective cohort study in the NHS North West region. QJM 2010; 103: 74958.

28. Granerod J, Ambrose HE, Davies NW, et al; UK Health Protection Agency (HPA) Aetiology of Encephalitis Study Group. Causes of encephalitis and differences in their clinical presentations in England: a multicentre, population-based prospective study. Lancet Infect Dis 2010; 10: 835-44.
29. Glaser CA, Honarmand S, Anderson LJ, et al. Beyond viruses: clinical profiles and etiologies associated with encephalitis. Clin Infect Dis 2006; 43: 1565-77.

30. Davison KL, Crowcroft NS, Ramsay ME, Brown DW, Andrews NJ. Viral encephalitis in England, 1989-1998: what did we miss? Emerg Infect Dis 2003; 9: 234-40.

31. Mori D, Ranawaka U, Yamada K, et al. Human bocavirus in patients with encephalitis, Sri Lanka, 2009-2010. Emerg Infect Dis 2013; 19: 1859-62.

32. Phan TG, Mori D, Deng X, et al. Small circular single stranded DNA viral genomes in unexplained cases of human encephalitis, diarrhea, and in untreated sewage. Virology 2015; 482: 98-104.

33. Gable MS, Sheriff H, Dalmau J, Tilley DH, Glaser CA. The frequency of autoimmune $\mathrm{N}$-methyl-d-aspartate receptor encephalitis surpasses that of individual viral etiologies in young individuals enrolled in the California encephalitis project. Clin Infect Dis 2012; 54: 899-904.

34. Seneviratne R de S, Navasivayam P, Perera S, Wickremasinghe RS. Microbiology of cerebral abscess at the neurosurgical unit of the National Hospital of Sri Lanka. Ceylon Med J 2003; 48: 14-6.

35. Peiris JS, Amerasinghe FP, Amerasinghe PH, Ratnayake $\mathrm{CB}$, Karunaratne SH, Tsai TF. Japanese encephalitis in Sri Lanka - the study of an epidemic: vector incrimination, porcine infection and human disease. Trans $R$ Soc Trop Med Hyg 1992; 86: 307-13.

36. Gunawardhana SAI, Somaratne SC, Fernando MA, Gunaratne PS. Tuberculous meningitis in adults: a prospective study at a tertiary referral centre in Sri Lanka. Ceylon Med J 2013; 58: 21-5.

37. de Gans J, van de Beek D; European Dexamethasone in Adulthood Bacterial Meningitis Study Investigators. Dexamethasone in adults with bacterial meningitis. NEngl J Med 2002; 347: 1549-56.

38. van de Beek D, de Gans J, McIntyre P, Prasad K. Steroids in adults with acute bacterial meningitis: a systematic review. Lancet Infect Dis 2004; 4: 139-43.

39. Brouwer MC1, McIntyre P, Prasad K, van de Beek D. Corticosteroids for acute bacterial meningitis. Cochrane Database Syst Rev 2013; 6: CD004405. doi: 10.1002/14651858.

40. Molyneux EM, Walsh AL, Forsyth H, et al. Dexamethasone treatment in childhood bacterial meningitis in Malawi: a randomised controlled trial. Lancet 2002; 360: 211-18.

41. Prasad K1, Singh MB. Corticosteroids for managing tuberculous meningitis. Cochrane Database Syst Rev 2008; 1: CD002244. doi: 10.1002/14651858.

42. Török ME, Nguyen DB, Tran TH, et al. Dexamethasone and long-term outcome of tuberculous meningitis in Vietnamese adults and adolescents. PLoS One 2011; 6: e27821.

43. Thwaites GE, Nguyen DB, Nguyen HD, et al. Dexamethasone for the treatment of tuberculous meningitis in adolescents and adults. NEngl J Med 2004; 351: 1741-51. 